\title{
FALSAFAH HIDUP BHAKTI MARGA YOGA DALAM NASKAH SÊRAT BHAGAWAD GITA
}

\author{
Doni Dwi Hartanto, Endang Nurhayati \\ Universitas Negeri Yogyakarta \\ endang_fbs@yahoo.com, donisvaha@gmail.com
}

\begin{abstract}
Abstrak
Penelitian ini bertujuan untuk melakukan interpretasi falsafah hidup Bhakti Marga Yoga dan interpretasi ajaran Bhakti Marga Yoga dalam naskah Sêrat Bhagawad Gita. Metode penelitian meliputi dua tahap, yaitu metode filologi dan metode kualitatif. Metode filologi dilakukan dengan tiga tahapan, yaitu transliterasi, suntingan, dan terjemahan teks. Metode penelitian kualitatif digunakan dalam interpretasi ajaran dan falsafah hidup teks. Sumber data penelitian ialah naskah berjudul Sêrat Bhagawad Gita. Analisis dilakukan dengan analisis deskriptif kualitatif. Validitas dan reliabilitas yang digunakan ialah validitas semantik dan reliabilitas (intrarater dan interrater). Hasil penelitian adalah sebagai berikut: (1) falsafah hidup Bhakti Marga Yoga yaitu (a) Yogi yang baik, (b) prinsip Bhakti Yoga, (c) cinta kepada Tuhan; dan (2) Bhakti Marga Yoga merupakan jalan yang ditempuh untuk mencapai kesempurnaan hidup dengan cara berbakti dan cinta kepada Tuhan.

Kata kunci: falsafah hidup, Bhakti Marga Yoga, Sêrat Bhagawad Gita
\end{abstract}

\begin{abstract}
This research aimed to interpretate Bhakti Marga Yoga philosophy of life and interpretate the doctrine of Bhakti Marga Yoga in the manuscript of Sêrat Bhagawad Gita. The research used philology and qualitative methods. Philological method was carried out in three stages, namely the transliteration, editing, and translation of text. Qualitative method was used to interpretate the philosophy of life and the value of the theaching of the text. The source of the data was a manuscript of Serrat Bhagawad Gita. Data was analyzed using qualitative descriptive analysis. Validation of data used semantic validity and reliability (intrarater and interrater). The result of this research are as follows. (1) The philosophy of life from Bhakti Marga Yoga is (a) the good Yogi, (b) the principle of Bhakti Yoga, (c) loving the Lord. (2) Bhkati Marga Yoga is the way to achieve the perfection of life by devoting and loving the God.
\end{abstract}

Keywords: philosophy of life, Bhakti Marga Yoga, Sêrat Bhagawad Gita

\section{ENDAHULUAN}

Kitab Bhagawad Gita merupakan susastra yang amat penting bagi masyarakat Hindu. Hal tersebut dikarenakan Kitab Bhagawad Gita merupakan intisari dari ajaran umat Hindu. Kitab Bhagawad Gita memuat banyak sekali ajaran yang dapat dijadikan pedoman bagi manusia untuk menjadikan dirinya menjadi pribadi yang semakin berkualitas. Salah satu ajaran yang termuat dalam kitab Bhagawad Gita ialah mengenai sebuah falsafah atau pandangan hidup yang dapat dijalankan oleh masyarakat agar dapat mencapai tujuan tertinggi dalam 
hidupnya. Ajaran tersebut ialah ajaran mengenai cara mencapai kesempurnaan hidup.

Ajaran mengenai hal-hal yang berkaitan dengan cara untuk mencapai kesempurnaan hidup dalam agama Hindu termuat dalam ajaran Catur Marga Yoga. Catur Marga Yoga merupakan empat jalan untuk mencapai kesempurnaan hidup, lahir maupun batin (Jagadhita dan Moksa) (Sukartha, Supartha, Sandiarta, Wiryani, 2003, p.37). Ajaran mengenai Catur Marga Yoga termasuk ke dalam Samanya Dharmasastra, yaitu etika agama Hindu yang universal dan dilaksanakan setiap harinya (Suhardana, 2010, p.5) Ajaran Catur Marga Yoga diantaranya Bhakti Yoga, Karma Yoga, Jñana Yoga, dan Raja Yoga. Salah satu ajaran dari Catur Marga Yoga yang mudah untuk dilaksanakan ialah ajaran Bhakti Marga Yoga. Kata bhakti berasal dari urat kata bhaj yang bermakna "cinta kasih" (Pudja, 2002, p.29). Bhakti Marga merupakan jalan yang digunakan untuk "mencari" Tuhan dengan sungguh-sungguh, sebuah cara untuk mencari Tuhan yang diawali, dilaksanakan, dan diakhiri dengan rasa cinta (Vivekananda, 1993 dalam Pudja, 2002, p.29).

Landasan yang digunakan dalam melaksanakan ajaran Bhakti Yoga diantaranya $\mathrm{Rg}$ Weda dan Bhagawad Gita. Bhakti Yoga merupakan jalan yang paling mudah dan paling umum dilaksanakan untuk mencapai moksa. Ada enam jenis bhakti yang disebut sebagai Bhavabhakti, yaitu: (1) Santabhava, yaitu bakti kepada orang tua; (2) Sakhyabhava, yaitu bentuk bakti dengan percaya kepada Sang Hyang Widhi serta segala manifestasinya sebagai teman yang selalu memberi pertolongan dan perlindungan, contohnya seperti Arjuna dengan Sri Kresna; (3) Dasyabhava, yaitu bakti kepada Tuhan layaknya bawahan kepada atasannya, seperti bakti Anoman kepada Sri Rama; (4) Vatsalyabhava, bakti seorang bhakta yang menganggap Tuhan layaknya putranya sendiri, seperti Yasoda kepada Kresna; (5) Kantabhava, bakti seorang bhakta layaknya seorang wanita kepada suaminya; (6) Madhuryabhava, wujud bakti sebagai rasa cinta yang suci dan tulus dari seorang bhakta kepada Tuhannya (Departemen Agama RI, 1994, p.83).

Selanjutnya, ada Sembilan cara yang dapat dilakukan untuk meningkatkan rasa bakti kepada Tuhan yang disebut sebagai Nawa Ratna Bhakti (Pudja, 2002, p.31). Uraian mengenai Nawa Ratna Bhakti disampaikan pada bagian berikut: (1) Srawanam, yaitu mendengarkan ajaran-ajaran dari kitab suci atau dari guru kerohanian; (2) Kirthanam, yaitu menghaturkan pujaan kepada Tuhan dengan melagukan nama-Nya; (3) Smaranam, selalu mengingat dan mengenang apa saja yang sudah diberikan oleh Tuhan; (4) Archanam, selalu bersembahyang kepada Tuhan; (5) Sevanam, yaitu memuji dan melayani Tuhan; (6) Dasyam, yaitu menjadi abdi Tuhan; (7) Vandanam, yaitu selalu bersyukur kepada Tuhan; (8) Sneham, yaitu tidak takut kepada Tuhan dengan cara menganggap Tuhan sebagai sahabat yang selalu memberi perlindungan; (9) Atmaniwedanam, yaitu selalu pasrah diri kepada Tuhan, artinya selalu menerima segala cobaannya.

Nilai-nilai filsafat dari konsep Bhakti Yoga dapat dipelajari untuk mengetahui bagaimana manusia dapat mencapai kesempurnaan hidup. Ajaran mengenai cara mencapai kesempurnaan dalam ajaran Bhakti Yoga ini selaras dengan ajaran masyarakat Jawa, yaitu konsep manunggaling kawula Gusti. Ajaran 
yang menguraikan tentang bagaimana cara manusia Jawa agar dapat menyatu dengan Tuhannya. Ajaran hidup ini sering disebut dengan istilah ngudi kasampurnan. Konsep mengenai ajaran Bhakti Yoga termasuk ke dalam konsep etika (susila) agama Hindu, yaitu salah satu dari Tri Kerangka Agama Hindu (filsafat, etika, ritual). Dengan demikian maka konsep Bhakti Yoga dapat dipastikan memiliki kaitan yang erat dengan konsep filsafat. Konsep filsafat yang akan dijelaskan ialah tentang falsafah hidup dari ajaran Bhakti Marga Yoga.

Falsafah merupakan cara manusia dalam meninjau makna dirinya, makna alam, dan tujuan hidupnya berdasarkan pikiran dan kepercayaannya. Falsafah dijadikan pedoman manusia untuk mencapai tujuan hidupnya (Nasroen dalam Wibawa, 2013a, pp.9-10). Falsafah hidup yang dijadikan pedoman dalam hidup manusia pada umumnya berkaitan dengan apa yang menjadi tujuan hidup manusia berdasar atas keyakinannya. Falsafah hidup pada setiap masyarakat tentu akan berbeda-beda. hal tersebut disebabkan oleh faktor bahwa kepercayaan yang dianut leh setiap masyarakat juga berbeda. Pada masyarakat Jawa, ajaran yang dijadikan falsafah hidup sering disebut dengan istilah filsafat Jawa. Filsafat Jawa merupakan sebuah pandangan hidup bagi masyarakat Jawa, yaitu sebuah asas yang diakui dan dipercayai oleh masyarakat Jawa, dan diteruskan kepada generasi selanjutnya sebagai pedoman hidup, serta menjadi ciri khas dan identitas masyarakat Jawa (Hadiatmaja \& Kuswa, 2010, p.61).

Masyarakat Jawa mempunyai falsafah hidup yang dijadikan pedoman dalam bertingkah laku, falsafah tersebut disebut filsafat Jawa. Filsafat Jawa merupakan sangkan paraning dumadi, artinya sebuah ajaran yang menunjukkan sebuah daya hidup yang disebut dengan "sukma", yang mencari pada sumber daya hidup yang disebut dengan kesempurnaan (Koesnoe, 1996, dalam Wibawa, 2013a, p53). Pendapat tersebut bermakna bahwa filsafat Jawa merupakan landasan dasar yang dijadikan pedoman dalam kehidupan masyarakat Jawa tujuan hidup yang akan dicapai oleh masyarakat Jawa.

Filsafat Jawa berpedoman pada prinsip/pandangan hidup tentang bagaimana manusia dapat mencapai kesempurnaan hidup. Filsafat dalam ajaran Hindu digunakan sebagai dasar untuk mencapai kesempurnaan (moksa). Baik falsafah hidup masyarakat Jawa maupun Hindu, keduanya sama-sama bertujuan untuk mencapai kesempurnaan hidup.

Kesempurnaan hidup, bagi masyarakat Hindu dapat dicapai apabila memiliki dasar kepercayaan yang mantab, yaitu dasar kepercayaan yang universal. Dasar kepercayaan masyarakat Hindu yang universal adalah Panca Sradha. Untuk mencapai filsafat tersebut umat Hindu melaksanakan salah satu ajaran Catur Yoga, yaitu Bhakti Yoga.

Konsep filsafat yang akan dijelaskan yaitu mengenai falsafah hidup, khususnya dalam konsep Bhakti Yoga yang terdapat dalam naskah Jawa, dengan Judul Sêrat Bhagawad Gita (SBG). Naskah atau manuskrip merupakan sebuah karangan yang ditulis tangan yang masih asli maupun salinannya, yang memuat teks atau rangkaian kata-kata sebagai bacaan dengan isi tertentu (Darusuprapta, 19841, p.9). Naskah Sêrat Bhagawad Gita merupakan naskah terjemahan dari bahasa Sansekerta yang ditulis oleh R. Ng. Hardjosapoetro. Naskah ini diterbitkan oleh Boekhandel Tan Khoen Swie. 
Bhagawad Gita merupakan percakapan yang dilakukan oleh Kresna dan Arjuna yang diceritakan dalam Bhisma Parwa dalam kitab Mahabharata. Bhagawad Gita tersusun dari 18 bab yang membahas rahasia langka Yoga, Vedanta, Bhakti, dan Karma (Sivananda, 2000, p.vii). Bhagawad Gita dapat diartikan sebagai Nyanyian Tuhan, hal ini karena naskah memuat pujaan-pujaan kepada Tuhan.

Pustaka Bhagawad Gita tersusun dari 700 sloka yang terbagi menjadi 18 bab, isinya terbagi menjadi tiga bagian pokok. Bagian-bagian dari Pustaka Bhagawad Gita dijabarkan sebagaimana berikut (Sudharta, 2010, p.71). Bagian 1, Bab I-VI, menjelaskan tentang disiplin kerja tanpa mengharapkan hasil dan juga sifat jiwa yang ada di dalam badan. Bagian 2, Bab VII-XII, menjelaskan disiplin ilmu dan kebhaktian kepada Brahman (Tuhan). Bagian 3, Bab XIII-XVIII, menjelaskan kesimpulan dari kedua bagian sebelumnya serta pengabdian seluruh jiwa dan raga serta kegiatan kerja yang ditujukan kepada Brahman.

Berdasar keterangan di atas, maka dibutuhkan langkah penelitian untuk menjelaskan isi dari naskah tersebut. Penelitian yang digunakan untuk menjelaskan isi dari naskah $S B G$ yaitu metode penelitian filologi. Langkahlangkah penelitian filologi yaitu inventarisasi naskah, deskripsi naskah, transliterasi teks, parafrase, dan terjemahan teks (Mulyani, 2012, p.3).

Filologi ialah sebuah ilmu yang mana objek penelitiannya ialah berupa naskah-naskah kuno (Djamaris, 1977, p.20). Hal tersebut berarti filologi mempelajari tentang naskah-naskah lama yang memuat tentang bahasa, sastra, maupun tentang kebudayaan sebuah bangsa. Pendapat tersebut didukung oleh pendapat dari Dasuki. Dasuki (1987, p.1) menjelaskan bahwa filologi adalah ilmu yang mempelajari segala segi kehidupan masa lalu seperti yang ditemukan dalam tulisan. Di dalamnya tercakup bahasa, sastra, adat-istiadat, sejarah, dan lainnya.

Berdasar pengertian dari para ahli tersebut, maka dapat disimpulkan bahwa filologi merupakan ilmu yang mempelajari naskah-naskah yang berkaitan dengan bahasa, sastra, maupun kebudayaan suatu bangsa. Objek kaji filologi secara spesifik terbagi menjadi dua, yaitu naskah dan teks. Naskah merupakan sesuatu yang konkret, sedangkan teks merupakan sesuatu yang abstrak (Baroroh-Baried, Soeratno, Sawoe, Sutrisno, Syakir, 1985, p.4). Hal ini menunjukkan bahwa teks merupakan isi dari naskah tersebut.

Langkah penelitian filologi yang dilakukan dalam penelitian ini, seperti yang sudah disampaikan sebelumnya, diawali dengan inventarisasi naskah. Inventarisasi naskah adalah membuat daftar seluruh naskah yang ditemukan, dengan studi katalog maupun dengan melihat langsung di perpustakaan (Djamaris dalam Mulyani, 2009, p.26). Langkah selanjutnya ialah deskripsi naskah, yaitu menjelaskan keadaan naskah yang bersifat fisik maupun non fisik (dilakukan pada naskah $S B G$ ). Langkah berikutnya melakukan transliterasi teks, yaitu mengganti aksara naskah menjadi aksara yang diinginkan, contohnya dari aksara Jawa menjadi aksara Latin, dan lain sebagainya (Saputro, 2008, p.103). Transliterasi yang digunakan dalam penelitian ialah transliterasi standar terhadap teks Panunggal sarånå Bêkti (Panêmbah).

Langkah keempat ialah suntingan teks dan aparat kritik. Metode suntingan yang digunakan ialah suntingan teks standar, yaitu suntingan yang dilakukan 
dengan membenarkan tulisan yang salah, tulisan yang tidak tetap, serta menyesuaikan ejaan dengan panduan ejaan yang digunakan. Aparat kritik (apparatus criticus) merupakan tanggung jawab ilmiah dari kritik teks yang dilakukan. Dalam hal ini aparat kritik bertujuan untuk menjelaskan teks yang sudah bersih dan tidak ada yang korup (Mulyani, 2009, p.29). Aparat kritik memuat kata-kata yang sudah disunting serta penjelasan dari kata-kata tersebut.

Langkah terakhir dalam penelitian filologi ini ialah melakukan terjemahan. Langkah parafrase tidak digunakan dalam penelitian karena teks dalam naskah sudah berbentuk gancaran. Terjemahan ialah mengganti bahasa dari bahasa teks atau bahasa sumber menjadi bahasa sasaran Mulyani, 2009, p.32). Metode terjemahan yang digunakan dalam penelitian ialah metode terjemahan harfiah, terjemahan isi, dan terjemahan bebas.

Sudah cukup banyak hasil terjemahan dari kitab Bhagawad Gita dari bahasa Sansekerta ke dalam bahasa yang lain, seperti bahasa Inggris dan bahasa Indonesia, akan tetapi tidak banyak hasil terjemahan dalam bahasa Jawa, apalagi yang berwujud naskah Jawa. Hal ini yang melatarbelakangi belum banyaknya penelitian-penelitian yang membahas naskah Bhagawad Gita yang berwujud naskah Jawa, sehingga penelitian tentang naskah $S B G$ penting untuk dilakukan, khususnya mengenai nilai-nilai filsafat yang terkandung dalam naskah Jawa tersebut. Nilai filsafat, khususnya tentang falsafah hidup sangat menarik, terlebih dalam masyarakat Jawa juga memiliki pandangan hidup yang hampir sama yaitu untuk mencapai kesempurnaan hidup. Dalam hal ini isi dari teks Panunggal sarånå Bêkti (Panêmbah) yang akan diteliti tentang falsafah hidupnya.

\section{METODE PENELITIAN}

Penelitian ini menggunakan metode penelitian kualitatif dan penelitian filologi. Penelitian kualitatif digunakan untuk menjelaskan tentang falsafah hidup Bhakti Marga Yoga yang terdapat dalam naskah Sêrat Bhagawad Gita. Penelitian ini juga menggunakan metode penelitian filologi karena data penelitian berupa naskah yang ditulis dengan aksara Jawa, sehingga pendekatan filologi bertujuan untuk menemukan data-data yang akan dianalisis dari konsep Bhakti Marga Yoga. Sumber data yang digunakan dalam penelitian ini adalah naskah Serat Bhagawad Gita yang ditulis oleh R. Ng. Hardjosapoetro.

Pengumpulan data dilakukan dengan langkah penelitian filologi, yaitu dimulai dengan inventarisasi naskah, deskripsi naskah, transliterasi teks, suntingan teks, dan terjemahan teks. Langkah penelitian filologi digunakan karena sumber data penelitian berupa naskah. Penelitian ini menggunakan tiga metode terjemahan. Tiga metode tersebut ialah metode terjemahan harfiah, terjemahan isi, dan terjemahan bebas. Terjemahan dalam penelitian ini dilakukan terhadap teks yang menggunakan bahasa Jawa, sehingga dilakukan dengan cara membuat alih bahasa dari teks berbahasa Jawa menjadi bahasa Indonesia. Instrumen yang digunakan dalam penelitian ini berupa kartu data.

Analisis data dilakukan dengan analisis kualitatif. Langkah analisis data dilakukan sebagai berikut. Reduksi data, dilakukan dengan memilah data dan memfokuskan data terhadap konsep Bhakti Marga Yoga, serta mereduksi data yang tidak berkaitan dengan Bhakti Marga Yoga. Klasifikasi data, dilakukan 
dengan menggolongkan data tentang Bhakti Marga Yoga di dalam teks. Display data, dilakukan dengan mengelompokkan data yang telah dibagi berdasar kategori yang sama. Penafsiran dan interpretasi dilakukan secara sistematis dan objektif berdasarkan teori filsafat dan Catur Marga Yoga, yang selanjutnya diuraikan secara deskriptif. Validitas yang digunakan ialah validitas semantik, yaitu memaknai kata-kata dan kalimat berdasarkan konteksnya. Untuk tahap reliabilitas, terbagi menjadi dua, yaitu reliabilitas intrarater dan interrater. Reliabilitas intrarater dilakukan dengan membaca teks berulang-ulang, sehingga mendapatkan data yang tetap. Reliabilitas interrater dilakukan dengan melakukan verifikasi data kepada ahli filologi, serta ahli agama Hindu.

\section{HASIL DAN PEMBAHASAN}

\section{Falsafah Hidup Bhakti Marga Yoga dalam Teks Panunggal sarånå Bêkti} (Panêmbah)

Teks Panunggal sarånå Bêkti (Panêmbah) (teks PB) memuat hal-hal yang berkaitan tentang hal-hal yang menjadi landasan dalam melaksanakan ajaran Bhakti Yoga, dalam hal ini, teks memuat tentang falsafah hidup Bhakti Marga Yoga. Wujud dari falsafah hidup dapat dikelompokkan sebagai berikut.

\section{Yogi yang baik}

Falsafah hidup yang pertama ialah melihat Yogi yang baik. Orang yang melaksanakan jalan Bhakti Marga disebut sebagai yogi atau bhakta. Orang yang menjadi bhakta senantiasa memasrahkan dirinya kepada Tuhan (Suhardana, 2010:26). Orang yang berbakti bermacam-macam jenisnya, akan tetapi seluruh jalan yang dilaksanakan oleh para yogi bertujuan sama, yaitu manunggal dengan Tuhan. Hal mengenai yogi yang baik yang dapat mencapai kesempurnaan disampaikan dalam teks $P B$ sloka 1 berikut.

/-/ Aturipun Arjunå /-/ //0// Tiyang bakti ingkang dados satunggal / sartå angajiaji ingkang ugi angluhurakên Padukå / utawi angluhurakên ingkang langgêng / tuwin ingkang botên gumêlar / yogi wau pundi ingkang langkung prayogi /-/ (Teks $P B$, sloka 1)

Berdasarkan sloka 1 tersebut, seorang yogi yang selalu menyembah dan memuja Tuhan atau yang mengagungkan yang abadi, mengagungkan yang Abstrak dapat manunggal dengan Tuhan. Semua yogi tersebut baik, akan tetapi yogi manakah yang lebih baik, itu menjadi sebuah pertanyaan bagi Arjuna yang ditujukan kepada Kresna.

Orang yang menyembah Tuhan dengan langsung dan penuh bakti disebut orang yang mengakui wujud Tuhan, sedangkan orang yang melaksanakan semadi kepada Tuhan yang tak berbentuk, disebut orang yang tidak mengakui wujud Tuhan. Hal tersebut membuat Arjuna bertanya kepada Kresna, manakah yogi yang lebih baik (Prabhupada, 2006, p.610). Selanjunya Kresna menjelaskan kawruh kepada Arjuna mengenai yogi yang dapat manunggal dengan Tuhan. Kresna juga menjelaskan tentang yogi yang menyembah Tuhan yang berwujud dan abstrak. Hal tersebut disampaikan dalam jawaban Kresna yang disampaikan dalam sloka berikut. 
/-/ Pangandikanipun Krêsnå / //0// Sing såpå pikiré tumuju maring Sun / kang tansah nunggal sartå angluhuraké Ingsun / kang ênggoné ngèlingi Ingsun mau jinarwå déning piandêlé / iku panunggal kang prayogå /-/ (Teks PB, sloka 2)

/-/ Ananging sing såpå tansah angluhuraké kang orå owah gingsir / kang orå tamtu / kang orå gumêlar / lan kang ngêndi-êndi ånå/ kang orå kênå kinirå-kirå / lan ajêg baé utåwå orå obah /-/ (Teks PB, sloka 3)

/-/ Sawusé mambêng sakèhing indriyané / lan orå ambédakaké sakabèhé / bungah mungguh karahayoné kabèh kahanan / iku ugå têkå maring Sun /-/ (Teks PB, sloka 4)

/-/ Sing såpå ciptané tumuju marang kang ora gumêlar / gêdhé bangêt pakèwuhé / sabab bisané anggayuh dalan kang ora gumêlar tumrap wong kang isih nganggo raga / iku måwå sangsårå /-/ (Teks PB, sloka 5)

/-/ Ananging sing såpå kabèh panggawéné pinasrahaké maring Sun / nganggêp Ingsun Kang Måhå Luhur / kanthi santoså panunggalé ing dalêm pamêlêng / iku angluhuraké Ingsun /-/ (Teks PB, sloka 6)

/-/ Lah Pritå Putrå / sing såpå pangèsthiné tumuju maring Sun / ora watårå suwé Ingsun bakal asung pamudharan marang dhèwèké såkå samodraning pati lan ubênging tumimbal lair /-/(Teks PB, sloka 7)

Berdasarkan sloka tersebut, orang yang pikirannya selalu tertuju kepada Tuhan, bersungguh-sungguh dalam memuja dan selalu mengagungkan Tuhan, dimana seluruhnya didasari oleh rasa yakin, itulah cara panunggal yang baik. Ada juga orang yang selalu mengagungkan sifat-sifat Tuhan (Yang Tetap, Yang Tidak Tetap, Yang Abstrak, Yang Ada Dimana-mana, serta Yang Tidak Terpikirkan) dengan penuh pengendalian indriya dan tidak membedakan apapun. Setelah ia mengendalikan indriyanya serta tidak membedakan segala hal lagi, senang akan kesejahteraan, ia juga akan mencapai kesempurnaan. Manusia yang pikirannya tertuju kepada Yang Abstrak, kesulitannya sangat besar. Hal tersebut karena jalan kesempurnaan yang dilaksanakan dengan badan jasmani harus dilalui dengan kesengsaraan.

Manusia yang segala perbuatannya selalu dipasrahkan kepada Tuhan, menganggap Tuhan Yang Maha Luhur dengan penuh keyakinan dalam melaksanakan panunggal, itu disebut mengagungkan Tuhan. Orang yang pikirannya selalu tertuju kepada Tuhan, ia juga akan mendapatkan kebebasan dari kelahiran yang berulang-ulang.

Uraian sloka 2-5 di atas menunjukkan bahwa yogi yang dapat mencapai kesempurnaan ialah yang selalu mengagungkan dan memuja Tuhan dengan segala sifatNya dengan penuh pengendalian terhadap panca indra dan memiliki keyakinan yang kuat. Uraian tersebut sesuai dengan pendapat Prabhupada (2006, p.612) yang menyampaikan bahwa manusia yang selalu memuja dengan keyakinan dan pengabdian merupakan yogi yang sempurna dalam melaksanakan yoga. Selanjutnya, selalu memuja Tuhan Yang Abstrak dan Tidak Terpikirkan merupakan salah satu tindakan yang melaksanakan pitutur masyarakat Jawa yaitu "Gusti Allah iku langgêng, tan kênå kinåyå ngåpå.” Artinya, Tuhan itu abadi dan tidak dapat diungkapkan dengan kata-kata (Hadiatmaja \& Kuswa, 2010, p.91). 
Uraian tersebut menunjukkan sifat Tuhan yang dipuja dengan rasa bakti dan keyakinan.

Selanjutnya, panunggal dilakukan dengan cara mengendalikan panca indra. Manusia yang melaksanakan jalan panunggal dengan badan jasmani harus merasakan kesengsaraan. Uraian tersebut sesuai dengan isi dari têmbang-têmbang Jawa yang menunjukkan laku dari janmå utåmå agar dapat mengendalikan indriyanya.

Kinanthi: "Dadiå lakunirèku, cêgah dhahar lawan guling, ... ."

Durmå: "Dipunsami ambanting sariranirå, cêgah dhahar lan guling, ... ."

Kedua kutipan têmbang dalam Sêrat Wulang Rèh tersebut merupakan contoh bahwa untuk mencapai kesempurnaan dengan menggunakan badan jasmani, pasti melalui kesengsaraan. Dijelaskan bahwa manusia harus mengurangi makan dan tidur. Uraian tersebut didukung dengan isi têmbang Sinom dalam Sêrat Wédhåtåmå berikut.

"Samangsané pasamuwan, mêmangun martå martani, sinambi ing sabên mångså, kålå kalaning ngasêpi, lêlånå téki-téki, nggayuh gêyonganing kayun, kayungyun êninging tyas, sanityåså pinrihatin, puguh panggah cêgah dhahar lawan néndrå."

Têmbang tersebut bermakna, bahwa ketika sedang berkumpul dalam sebuah pertemuan, haruslah membangun perasaan yang menyejukkan bagi sesamanya. Pada saat-saat tertentu melakukan semadi di tempat yang sepi agar hatinya menjadi hening (wêning), sehingga orang tersebut haruslah berlaku prihatin dengan cara mengurangi makan dan tidur (Hadiatmaja, 2011, p.54). Uraian tersebut menunjukkan bahwa orang yang melakukan tapa (untuk mencapai kesempurnaan dengan badan jasmani), itu dilaksanakan dengan penuh prihatin.

Uraian sloka 6-7 bermakna bahwa Tuhan akan memberikan pembebasan dari kelahiran yang berulang-ulang kepada manusia yang seluruh perbuatannya dipasrahkan kepada Tuhan, serta senantiasa mengagungkan Tuhan dengan penuh keyakinan. Kelahiran dan kematian yang berulang-ulang tidak akan pernah ada habisnya. Hal tersebut yang menyebabkan kesengsaraan bagi manusia, akan tetapi manusia harus dapat terbebas dari kesengsaraan tersebut agar dapat mencapai moksa. Hal tersebut dilakukan dengan cara memasrahkan diri kepada Tuhan, mengagungkan Tuhan, serta selalu memuja Tuhan (Suhardana, 2010, p.56). Pasrah kepada Tuhan bukan berarti manusia meninggalkan kewajibannya, akan tetapi memasrahkan segala hasil perbuatannya kepada Tuhan.

\section{Prinsip Bhakti Yoga}

Falsafah hidup selanjutnya ialah ajaran mengenai prinsip dari Bhakti Yoga. Bhakti Yoga merupakan jalan untuk mencapai kesempurnaan dengan sarana memasrahkan diri kepada Tuhan. Hal tersebut yang membuat Bhakti Yoga sebagai jalan kesempurnaan dengan rasa cinta yang ditujukan kepada Tuhan. Uraian mengenai Bhakti Yoga disampaikan dalam sloka berikut. 
/-/ Pikirirå lêboknå sakjroning Sun / budinirå tumujuå maring Sun / uwis mêsthi / sirå ing têmbé dumunung ing jêroning Sun /-/ (Teks PB, sloka 8)

/-/ Ananging manåwå pikiré marang Ingsun durung biså santoså / Arjunå / banjur ngangkahå têkan Ingsun / sarånå sinau anunggal /-/ (Teks PB, sloka 9)

/-I Yèn sirå ugå isih durung biså nglakoni / cukup sarupaning panggawènirå / lêladi maring Sun samêktanånå / yèn sirå anindaki sagunging panggawé kang margå Ingsun / iyå bakal biså anggayuh kasampurnan /-/ (Teks PB, sloka 10)

/-/ Yèn sirå ugå isih durung biså nglakoni mangkono / banjur anglakonånå mangrèh pribadinirå / angêdohånå wohing kabèh panggawé /-/ (Teks PB, sloka 11)

/-/ Kawruh iku angungkuli sinau / kang ngluwihi kawruh iku pamêlêng / kang ngungkuli pamêlêng iku angêdohi kabèh panggawéné / sawusé pisah såkå wohing panggawé / sirå banjur tumuli antuk katêntrêman /-/(Teks PB, sloka 12)

Berdasarkan sloka tersebut, manusia harus fokus dalam memikirkan Tuhan dan seluruh kepandaiannya ditujukan kepada Tuhan. Manusia yang senantiasa memikirkan Tuhan akan manunggal dengan Tuhan. Akan tetapi, jika pikirannya belum mantap, manusia harus berusaha dengan cara belajar panunggal. Apabila masih belum bisa terlaksana, cukup dengan memasrahkan seluruh hasil perbuatannya kepada Tuhan. Dengan menjadikan rasa bakti sebagai landasan perbuatannya, manusia akan dapat mencapai kesempurnaan.

Selanjutnya, apabila manusia belum dapat melaksanakan ajaran tersebut, ia cukup melatih dirinya agar menjauhi segala hasil perbuatannya. Kawruh lebih tinggi dari pada pemusatan pikiran. Meditasi lebih tinggi dari kawruh, sedangkan yang tertinggi ialah mengikhlaskan seluruh hasil perbuatannya. Setelah ia mengikhlaskan hasil perbuatannya manusia akan mencapai kententraman.

Uraian sloka tersebut mengindikasikan bahwa manusia yang melaksanakan prinsip Bhakti Yoga adalah dengan senantiasa memuja Tuhan. Seluruh pikiran tertuju hanya kepada Tuhan. Apabila piwulang tersebut belum dapat dilaksanakan, manusia harus belajar agar dapat manunggal dengan Tuhan. Piwulang tersebut sesuai dengan pitutur masyarakat Jawa yang tertuang dalam têmbang Sinom Sêrat Wédhåtåmå berikut.

"Nulådå laku utåmå, tumrapé wong Tanah Jawi, wong Agung ing Ngèksigåndå, Panêmbahan Sénåpati, kapati amarsudi, sudaning håwå lan nêpsu, pinêsu tåpå bråtå, tanapi ing siyang ratri, amêmangun karyénak tyasing sasåmå."

Têmbang tersebut bermakna bahwa masyarakat Jawa harus mencontoh perilaku utama yang dilakukan oleh Panembahan Senopati, yang selalu tekun dalam mengurangi napsu dengan melakukan tapa siang dan malam, serta berusaha menyenangkan sesamanya (Wibawa, 2013a:127). Uraian tersebut dapat diartikan bahwa manusia yang akan melaksanakan panunggal harus sering bertapa untuk mengasah hatinya agar senantiasa ingat kepada Tuhan. Uraian tersebut juga selaras dengan piwulang sêmbah jiwå dalam tembang Gambuh Sêrat Wédhåtåmå berikut. 
"Samêngko kang tinutur, sêmbah katri kang sayêkti katu, mring Hyang Sukmåsukmanên saari-ari, arahé dipunkacukup, sêmbah ing jiwå suténggong."

"Sayêkti luwih prêlu, ingaranan pêpuntoning laku, kalakuwan kang tumrap bangsaning batin, suciné lan awas émut, mring alaming låmå amot."

"Ruktiné ngangkah kukut, ngikêt ngrukêt trilokå kakukut, jagat agung ginulung lan jagat cilik, dén kandêl kumandêl kulup, mring kêlaping alam kono."

Ketiga bait têmbang Gambuh tersebut bermakna bahwa, sembah yang ketiga merupakan sembah yang dihaturkan kepada Tuhan. Seluruhnya sudah disampaikan di sêmbah jiwå. Sejatinya, sêmbah jiwå merupakan akhir dari seluruh sembah. Segalanya berkaitan dengan batin, jiwanya senantiasa suci dan selalu ingat kepada Tuhan. Caranya dengan melaksanakan sêmbah jiwå dengan melakukan konsentrasi cipta, rasa, dan karsanya kepada Tuhan dari dalam kalbu (Wibawa, 2013a, pp.133-134). Sêmbah jiwå dapat dilaksanakan jika manusia sudah melaksanakan sêmbah rågå dan sêmbah ciptå.

Selanjutnya, apabila manusia yang tidak melaksanakan panunggal dengan cara tapa (semadi), manusia dapat melaksanakan panunggal dengan memasrahkan seluruh hasil perbuatannya. Sejatinya, mengikhlaskan seluruh hasil perbuatan merupakan hal yang paling luhur. Dengan mengikhlaskan seluruh hasil perbuatan tersebut manusia dapat mencapai kesempurnaan.

Cinta kepada Tuhan

Falsafah hidup yang terakhir ialah mencintai Tuhan. Telah disampaikan sebelumnya bahwa Bhakti Yoga merupakan jalan untuk mencapai kesempurnaan dengan rasa bakti dan cinta kepada Tuhan. Bakti kepada Tuhan merupakan cara yang paling baik untuk mencapai tujuan hidup. Bakti kepada Tuhan akan menghasilkan kesehatan, kemuliaan, dan kesejahteraan (Suhardana, 2010:182). Hal-hal yang dapat disebut sebagai rasa cinta kepada Tuhan disampaikan dalam sloka berikut.

/-/ Sing såpå ora gêthing / sartå wêlas asih marang sawiji-wijining dumadi tanpå pèpènginan lan kamurkan / dhêmên ngapurå nganggêp lårå lan prihatin pådhå baé /-/ (Teks PB, sloka 13)

/-/ Tansah narimå / anggung anglakoni panunggal / angrèh pribadiné / sêtyå tuhu / pikir lan budiné tumuju lan nunggal maring Sun / bakti kang mangkono mau pratåndhå asih maring Sun /-/ (Teks PB, sloka 14)

/-/ Sing såpå wus ora kéguh déning kadonyan / lan kang ora munasikå ing donyå / såpå kang wus uwas såkå êndêming kasênêngan / nêpsu / lan wêdi / iku dhèwèké asih maring Sun /-/ (Teks PB, sloka 15)

/-/ Sing såpå tånpå pangarêp-arêp / sukci / pintêr / sêpi ing pamrih / lan kang såpå kuwuré wus sirnå / sèlèh sakliring panggawé / bakti kang mangkono iku asih maring Sun /-/(Teks PB, sloka 16)

/-/ Sing såpå ora duwé bungah utåwå gêthing / ora sêdhih / utåwå ora duwé pénginan / ålå bêcik pinasrahaké kaèbêkan bakti / iyå iku asih maring Sun /-/ (Teks PB, sloka 17) 
/-/ Sing såpå ora ambédakaké mungsuh lan mitrå / pangaji-aji lan panyamah adhêm lan panas / sêdhih lan lårå wus pådhå baé / luwar såkå ing karêm /-/ (Teks $P B$, sloka 18)

/-/ Sing såpå ora ambédakaké panacad lan pangalêm / antêng / narimå åpå kang tinåmpån / ora omah-omah santoså pikiré / kaèbêkan ing bêkti / wong mau asih maring Sun /-/ (Teks PB, sloka 19)

/-/ Sing såpå têmên mangudi anggêr-anggêr kang langgêng iyå kang ing kéné winarahaké / kalayan pracåyå / kang mangkono mau bangêt asih maring Sun /-/ (Teks PB, sloka 20)

Berdasarkan sloka tersebut, salah satu bentuk bakti ialah tidak memiliki rasa benci, berbelas kasih kepada sesama, tidak memiliki keinginan dan angkara, suka memberi maaf, dan menganggap sakit ataupun prihatin adalah sama. Yang senantiasa menerima saat melakukan panunggal, dirinya selalu setia dan pasrah, selalu memikirkan Tuhan, itulah tanda bahwa cinta kepada Tuhan. Manusia yang sudah menjauh dari hal-hal duniawi, tidak akan terpengaruh oleh napsu dan rasa takut, itu juga merupakan tanda cinta kepada Tuhan.

Siapa yang tidak memiliki keinginan, suci, pandai, sêpi ing pamrih, rasa bingungnya telah hilang, bakti tersebut merupakan wujud cinta kepada Tuhan. Siapa yang tidak membedakan senang dan susah, tidak sedih atau iri, baik dan buruk diserahkan kepada Tuhan dengan penuh rasa bakti, itu adalah wujud bakti kepada Tuhan. Siapa yang tidak membedakan musuh dan teman, pujian dan hinaan, dingin dan panas, sedih dan sakit dianggap sama, ia adalah orang yang telah terbebas dari segala keinginan.

Siapa yang tidak membedakan hinaan dan pujian, tenang, menerima apa yang diperoleh, terbebas pikirannya karena penuh rasa syukur, itu tanda cinta kepada Tuhan. Siapa yang dalam melaksanakan tapa kepada Tuhan didasari rasa keyakinan yang kuat, bakti tersebutlah yang menunjukkan cinta kepada Tuhan.

Uraian tersebut bermakna bahwa manusia yang sudah tidak memiliki rasa benci, selalu berbelas kasih, tidak iri, dan selalu menerima apa yang diperoleh saat melaksanakan panunggal, menganggap sakit dan prihatin adalah sama, itulah yang disebut cinta kepada Tuhan. Manusia yang cinta kepada Tuhan adalah manusia yang tidak terpengaruh lagi kepada hal-hal yang bersifat duniawi, terbebas dari hawa napsu, serta rasa takut. Tidak memiliki keinginan, suci, pandai, tidak mengharapkan hasil, tidak membedakan rasa senang dan susah, sedih, dan segalanya senantiasa diserahkan kepada Tuhan.

Manusia yang mencintai Tuhan juga tidak membedakan antara musuh dan teman, pujian dan hinaan, sedih dan sakit, telah terbebas dari segala keinginan. Tidak membedakan hinaan dan pujian, selalu tenang dan menerima apapun, yakin dan mantap keyakinannya, itulah bakti kepada Tuhan. Manusia yang seperti itu dan selalu berkeinginan untuk mencapai kelanggengan dengan dasar keyakinan yang benar dapat mencapai ketentraman.

Piwulang yang disampaikan dalam uraian tersebut sesuai dengan pitutur masyarakat Jawa yaitu "åjå bungah yèn dialêm, åjå susah yèn dicacad." Artinya, menjadi manusia harus selalu rendah hati, manusia pasti memiliki kekurangan, sehingga manusia harus selalu mawas diri (Hadiatmaja, 2011, p.70). Manusia 
harus mengetahui apa yang kurang dan apa yang lebih dari dirinya. Ajaran tersebut selaras dengan pitutur lainnya, yaitu "lilå lamun kêtaman, kélangan nora gêgêtun." Artinya, manusia harus ikhlas dan lêgawa apabila mendapatkan cobaan, apabila kehilangan sesuatu tidak boleh kecewa. Ajaran tersebut bermakna bahwa apabila manusia mendapatkan cobaan harus menerimanya dengan hati yang ikhlas.

Piwulang tersebut selaras dengan piwulang sêmbah råså dalam Sêrat Wédhåtåmå. Piwulang sêmbah råså tidak menekankan pada kegiatan ritual yang menjadi pusat aktivitas, akan tetapi seluruh badannya harus dengan rasa pasrah dalam melaksanakan kewajiban. Hal tersebut termasuk melaksanakan kewajiban dengan sungguh-sungguh, tidak ragu-ragu, dan yakin bahwa seluruh perbuatannya ditujukan untuk ketentraman hidup. Hal mengenai ajaran sêmbah råså disampaikan dalam pupuh Gambuh berikut.

"Samêngko ingsun tutur, gantyå sêmbah ingkang kaping catur, sêmbah råså karånå rosing dumadi, dadiné wis tanpå tuduh, mung kalawan kosing batos."

"Kalamun durung lugu, åjå pisan wani ngaku-aku, antuk siku kang mêngkono iku kaki, kênå ugå wênang muluk, kalamun wus pådhå mêlok.”

"Mêloké ujar iku, yèn wus ilang sumêlanging kalbu, amung kandêl kumandêl marang ing takdir, iku dén awas dén émut, dén mêmêt yèn arså momot."

Têmbang tersebut bermakna, sêmbah råså merupakan sembah yang keempat (yang terakhir). Yang disebut "rasa" ialah keadaan batin yang paling halus yang berada dalam pribadi manusia yang tidak dapat dilihat kecuali dengan kekuatan batin yang besar. Apabila belum pernah melaksanakan jangan sampai sombong, karena akan mendapatkan balasannya (karma). Manusia boleh memberi petunjuk/pitutur apabila sudah benar mengetahui kawruh yang sejati. Kenyataan yang dibahas tersebut, apabila sudah hilang keragu-raguan hatinya, hanya percaya dengan sungguh-sungguh kepada takdir. Hal tersebut harus diawas dan diingat dengan cermat apabila ingin menguasai seluruh ilmu/kawruh (Wibawa, 2013, pp.134-135). Piwulang sêmbah råså tersebut merupakan sembah yang tertinggi, umumnya dilaksanakan oleh orang yang sudah dapat melaksanakan tiga tingkatan sembah yang sebelumnya, yaitu sêmbah rågå, sêmbah ciptå, dan sêmbah jiwå.

\section{Ajaran Bhakti Marga Yoga dalam Sêrat Bhagawad Gita}

Ajaran Bhakti Marga Yoga dijabarkan dalam teks Panunggal sarånå Bêkti (Panêmbah) (teks $P B$ ). Jalan panunggal ini merupakan dasar dari seluruh jalan panunggal dalam piwulang Catur Marga Yoga. Rasa bakti dan cinta kepada Tuhan menjadi landasan yang penting untuk melaksanakan seluruh piwulang panunggal. Berdasarkan uraian dari nilai-nilai falsafah hidup yang telah disampaikan sebelumnya, piwulang Bhakti dapat dilaksanakan dalam kehidupan sehari-hari sebagaimana berikut.

Pertama, yogi yang baik. Banyak sekali pembahasan yang memuat tentang bagaimana manusia dapat manunggal dengan Tuhan padahal telah diketahui bahwa "Gusti iku tan kênå kinåyå ngåpå." Berdasarkan sloka Bhagawad Gita, memuja Tuhan yang berwujud maupun yang tidak berwujud adalah sama. perbedaan hanya terletak kepada siapa yang melaksanakan panembah itu. Orang- 
orang bijak pada umumnya menyembah Tuhan yang tidak berwujud, hal tersebut dikarenakan mereka sudah "berilmu". Sedangkan bagi orang yang belum cukup ilmunya, umumnya mereka menyembah Tuhan dengan cara mewujudkan Tuhan dalam beraneka macam bentuk, seperti arca maupun pratima. Seluruh panunggal dengan menyembah Tuhan yang berwujud maupun tidak adalah panunggal yang baik selama dilaksanakan dengan rasa bakti.

Dua, prinsip Bhakti Yoga. Berdasarkan sloka yang telah disampaikan sebelumnya, Bhakti Yoga dilakukan dengan cara pemusatan pikiran kepada Tuhan. Orang yang tidak dapat melaksanakan tersebut harus belajar panunggal, apabila belum dapat melaksanakan seluruh piwulang panunggal, cukup dengan memasrahkan seluruh perbuatannya dengan bakti dan cinta kepada Tuhan untuk mencapai kententraman.

Tiga, senantiasa mencintai Tuhan. Manusia yang senantiasa yakin dalam melaksanakan panunggal, pikirannya tidak ragu-ragu, tidak membedakan apapun, itulah yang disebut mencintai Tuhan. Jalan panunggal ini juga menjadi dasar bagi seluruh jalan panunggal. Rasa cinta kepada Tuhan sebagai landasan dalam memuja Tuhan, sehingga manusia yang memuja Tuhan disebabkan oleh rasa cinta dan kasih sayang, bukan karena rasa takut.

Piwulang-piwulang Bhakti Yoga yang telah disampaikan di atas masih sering ditemukan dalam kehidupan sehari-hari. Contoh-contoh yang menunjukkan piwulang dari Bhakti Yoga oleh umat Hindu ialah senantiasa melaksanakan kewajiban dalam melaksanakan ibadah kepada Tuhan melalui sembahyang, melaksanakan yadnya, melantunkan nyanyian pujaan kepada Tuhan, dan lain sebagainya.

Keempat jalan panunggal tersebut seluruhnya baik untuk dilaksanakan. Semua manusia tidak dibatasi harus melaksanakan jalan panunggal yang mana, akan tetapi penting untuk dipahami bagi orang-orang yang akan melaksanakan jalan panunggal ialah kekuatan masing-masing. Manusia harus menyesuaikan jalan panunggal yang akan dilaksanakan dengan kekuatan pribadinya. Selama manusia melaksanakan jalan panunggal dengan sungguh-sungguh, menjauhi halhal yang berkaitan dengan duniawi, selalu berlandaskan darma dan melaksanakan piwulang subha karma, manusia akan mencapai kesempurnaan (moksa).

\section{PENUTUP}

Berdasarkan hasil penelitian dan pembahasan, dapat diambil kesimpulan sebagai berikut. Pertama, transliterasi teks menghasilkan teks Panunggal sarånå Bêkti (Panêmbah) yang ditulis dengan menggunakan aksara Latin. Kedua, suntingan teks menghasilkan teks Panunggal sarånå Bêkti (Panêmbah) yang sudah bersih dari kesalahan penulisan. Ketiga, terjemahan teks mengahasilkan teks Panunggal sarånå Bêkti (Panêmbah) berbahasa Indonesia, sedangkan katakata yang tidak dapat diterjemahkan dijelaskan dalam catatan terjemahan.

Keempat, falsafah hidup Bhakti Marga Yoga yang termuat dalam teks Panungal sarånå Bêkti (Panêmbah) terbagi menjadi tiga falsafah, yaitu (1) yogi yang baik, (2) prinsip Bhakti Yoga, dan (3) mencintai Tuhan. Kelima, ajaran dari Bhakti Marga Yoga yang terdapat dalam SBG ialah manusia harus senantiasa mencintai Tuhan dan berbakti kepada Tuhan. Manusia dalam berbuat harus senantiasa diawali, dilaksanakan, dan diakhiri dengan rasa bakti kepada Tuhan. 


\section{DAFTAR PUSTAKA}

Baroroh-Baried, S., Soeratno, S. C., Sawoe, Sutrisno, S., Syakir, M. (1985). Pengantar Teori Filologi. Jakarta: Pusat Pembinaan dan Pengembangan Bahasa Departemen Pendidikan dan Kebudayaan.

Darusuprapta. (1984). Beberapa Masalah Kebahasaan Dalam Penelitian Naskah. Ceramah Kebahasaan dan Kesastraan Balai Penelitian Bahasa.

Dasuki, Sholeh. (1987). Filologi dan Penulisan Sejarah. Makalah dana Pertemuan Ilmiah Bahasa dan Sastra Indonesia IX Se-DIY dan Jawa Tengah di Universitas Tidar Magelang.

Djamaris, Edwar. (1977). Filologi dan Cara Kerja Penelitian Filologi. Jakarta: Proyek Penelitian Bahasa dan Sastra Indonesia dan Daerah Pusat Pembinaan dan Pengembangan Bahasa Departemen Pendidikan dan Kebudayaan.

Hadiatmaja, Sarjana. (2011). Etika Jawa. Yogyakarta: Grafika Indah.

Hadiatmaja, Sarjana \& Endah, Kuswa. (2010). Filsafat Jawa. Yogyakarta: Kanwa Publisher.

Departemen Agama RI. (1994). Buku Pelajaran Agama Hindu untuk Perguruan Tinggi. Jakarta: Hanuman Sakti.

Hardjosapoetro. (1929). Serat Baghawad Gita. Kediri: Boekhandel Tan Khoen Swie.

Kaelan. M. S. 2005. Metode Penelitian Kualitatif Bidang Filsafat. Yogyakarta: Paradigma.

Mulyani, Hesti. (2009). Teori Pengkajian Filologi. Diktat Kuliah. Jurusan Pendidikan Bahasa Daerah Fakultas Bahasa dan Seni UNY. Publisher. (2012). Membaca Manuskrip Jawa. Yogyakarta: Kanwa

Prabhupada, Sri Srima A.C. Bhaktivedanta Swami. (2006). Bhagawad-gita As It Is. Jakarta: The Bhaktivedanta Book Trust International Inc.

Pudja, Ida Bagus. (2002). Buku Pelajaran Agama Hindu untuk Perguruan Tinggi. Yogyakarta: UNY Press.

Saputro, Karsono H. (2008). Pengantar Filologi Jawa. Jakarta: Penerbit Wedatama Wudya Sastra.

Sivananda. (2000). Bhagavad Gita. Himalaya: The Devine Life Society.

Sudharta, Tjokorda Rai. (2010). Bhagawad Gita dalam Bhisma Parwa. Denpasar: Widya Dharma.

Suhardana, K. M. (2010). Catur Marga: Empat Jalan Menuju Brahman. Surabaya: Pāramita.

Sukartha, I. K., Supartha, I.N.S., Sandiarta, I.M., Wiryani, N. W. (2003). Agama Hindu untuk SLTP Kelas 3 (Semester 1 dan 2). Jakarta: Ganeca Exact.

Wibawa, Sutrisna. (2013a). Filsafat Jawa. [Versi Elektronik] diunduh dari http://staff.uny.ac.id/sites/default/files/pendidikan/Dr.\%20Sutrisna\%20Wi bawa,\%20M.Pd./BUKU\%20FILSAFAT\%20JAWA\%20UTUH-

Gabung.PDF pada hari Senin, 14 Desember 2015 pukul 07.39 WIB. Yogyakarta. UNY. 